\title{
O Papel da Logística no Comércio Eletrônico
}

\author{
André Luiz da Silva França - andre_silvaah@outlook.com ${ }^{1}$ \\ Djanilson Francisco da silva - djanilson@gmail.com ${ }^{1}$ \\ Wendel Felipe Gomes de Souza - wendel@gmail.com ${ }^{1}$ \\ Adeilde Francisca de Santana - adeildefsantana@hotmail.com ${ }^{1}$ \\ Jessé Araújo Barbosa - jessebarbosa11@hotmail.com ${ }^{1}$
}

\begin{abstract}
Resumo - Este estudo tem por objetivo definir o papel da logística dentro do cenário do comércio eletrônico. A logística melhora o nível de rentabilidade nos serviços de distribuição aos clientes e aos consumidores e contribui para a eficiência do comércio eletrônico. A metodologia utilizada na realização deste trabalho foi uma pesquisa bibliográfica exploratória descritiva onde foi evidenciado as variáveis: distribuição, transporte, informação e comercialização eletrônica. Os dados apontaram que o comercio eletrônico teve uma evolução muito significativa, tendo uma perspectiva crescente de evolução firmada em $12 \%$ com relação ao ano de 2017 , totalizando R \$ 53,5 Bilhões de lucro com as transações comerciais eletrônicas. Através disso conclui-se que o papel da logística é primordial para assegurar a satisfação e fidelização do cliente
\end{abstract}

Palavras-chave: Logística, Comércio eletrônico, Tecnologia.

\section{The Role of Logistics in Electronic Commerce}

\begin{abstract}
This study aims to define the role of logistics within the e-commerce scenario. Logistics improves the level of profitability in distribution services to customers and consumers and contributes to the efficiency of e-commerce. The methodology used in this work was a descriptive exploratory bibliographic research where the following variables were evidenced: distribution, transportation, information, and electronic marketing. The data pointed out that e-commerce had a very significant evolution, with a growing perspective of $12 \%$ growth in relation to 2017, totaling R \$ 53.5 Billion profit with electronic commercial transactions. This concludes that the role of logistics is paramount to ensure customer satisfaction and loyalty.
\end{abstract}

Keywords: Logistics. E-commerce, Information Technology. 


\section{INTRODUÇÃO}

As mudanças recorrentes do avanço tecnológico no ambiente empresarial, impactaram intensamente no que diz respeito a maneira das organizações comercializarem seus produtos e serviços. Sabe-se que antes, o modo de comercialização era totalmente diferente, onde toda a relação de compra era feita de forma presencial, logo, se o cliente quisesse obter algum produto e/ou serviço, deveria deslocar-se de onde estava e ir em direção ao fornecedor e assim procurar/ adquirir o que desejar, gerando assim, uma perca significativa de tempo.

No entanto, com o passar dos anos, o avanço nos meios de comunicação e tecnologia possibilitou uma nova forma de comercialização, o e-commerce. Esse método de comercializar os produtos e serviços eletronicamente, possibilitou aos consumidores uma facilidade no que se diz respeito a adquirir o que bem desejar sem precisar se locomover de onde está, precisando apenas de um smartphone, notebook, ou computador com acesso à internet.

\footnotetext{
Devido à velocidade de crescimento e por trazer novas formas de comunicação, a internet muda a forma de conceber e realizar negócios nas organizações, permitindo, além de interações entre pessoas, povos e culturas, o delineamento de um novo modelo de negócios. Com ela, as organizações podem definir critérios de atuação em um ambiente competitivo onde "o mais rápido é melhor que o maior" (FORGE, 1993, p. 493, apud TESTA, LUCIANO e FREITAS, 2007)
}

Com isso, pode-se perceber que o cenário atual, possibilita a agilidade das relações comerciais, no entanto, ao mesmo tempo cobra rapidez em seus processos. (FORGE, I993, p. 493, apud TESTA, LUCIANO e FREITAS, 2007).

Todavia, vale a pena acrescentar que mesmo com todo esse avanço tecnológico nas relações comerciais, ainda existe uma lacuna que deve ser preenchida, ou seja, uma problemática a ser resolvida, a logística.

Nesse cenário evolutivo, a logística se torna imprescindível no que diz respeito ao atendimento dos pedidos realizados eletronicamente, pois as empresas após realizarem as vendas pela internet, necessitam estruturar seus processos de preparação e distribuição dos produtos de forma eficiente e eficaz, para que assim tudo ocorra de forma a satisfazer as duas partes do negócio, ou seja, a empresa e os clientes. Nessa lógica, o objetivo central desse artigo é definir o Papel da Logística no comércio eletrônico e como objetivos específicos; definir o conceito e surgimento do comércio eletrônico; b) discorrer sobre alguns tipos de comércio eletrônico; c) Escrever sobre os indicadores de crescimento do e-commerce; e)Definir infovias, seu surgimento e importância dentro da logística do e- commerce. Imagina-se que gerenciando a logística do e-commerce de maneira eficiente e eficaz, as organizações atuantes no cenário mercadológico eletrônico ganharão espaço nesse mercado altamente competitivo. 


\section{REFERENCIAL TEÓRICO}

\subsection{Origem e definição do comércio eletrônico}

O comércio eletrônico veio aparecer na sociedade através da evolução das tecnologias na internet, tendo por objetivo auxiliar no que diz respeito a agilidade das vendas e também extinguir intermediários da cadeia de suprimentos, expandindo as áreas de alcance dos consumidores e fornecedores de produtos ou serviços (FIGUEIREDO, 2009). O autor ao referir-se sobre o comércio eletrônico diz: "Não é só pela internet através de conexão com computadores, mas por meio de anúncios na televisão e principalmente o uso de aparelhos celulares e outros equipamentos eletrônicos" (FIGUEIREDO, 2009, P.I).

Assim compreende-se que a evolução tecnológica impactou em inúmeras áreas no que diz respeito ao desenvolvimento das organizações, com uma intensificação na questão da comercialização de seus produtos e/ou serviços, ou seja, o avanço tecnológico possibilitou e ao mesmo tempo exigiu das empresas uma infraestrutura mais sofisticada, para que assim, as mesmas pudessem estar cada vez mais vistas no mercado, e também, pudessem manter sua relação empresa-cliente cada vez mais estreita.

Com isso pode-se entender que o cenário mercadológico atual com toda a evolução permitiu que hoje, as empresas pudessem expor seus produtos e/ou serviços através da internet, aumentando assim a sua exposição a clientela e ao mesmo tempo ampliar seu espaço no mercado. No entanto compreende-se também que para que tudo isso venha acontecer, se faz necessário que as organizações se adequem a evolução mercadológica em questão, munida de toda a estrutura a nível de operacionalização e tecnologia possível, sistematizando seus processos, mais precisamente no que diz respeito a propagação dos produtos/serviços nos sites e na intensificação do relacionamento com o cliente, para que assim a comercialização eletrônica possa fluir da melhor maneira possível (NAKAMURA, 20II, p.IO).

Deste modo percebe-se que o avanço tecnológico possibilitou, sobretudo, a formação de uma necessidade de expansão por parte das organizações no que diz respeito as transações comerciais, e hoje, as empresas têm a necessidade de estarem também atuantes no ramo do comércio eletrônico, uma vez que fazendo isso, as mesmas estarão cada vez mais perto de sua clientela e certamente melhorará suas relações de compra e venda, ganhando assim o espaço desejado dentro do cenário competitivo do mercado em que está inserida. ( FLEURY,2000).

Para Nakamura (20II) o comércio eletrônico:

Trata-se de todos os processos envolvidos da cadeia de valor realizada num ambiente eletrônico, utilizando de ferramentas com grande tecnologia deinformação e de comunicação, tendo como principal objetivo atender as necessidades exigidaspelos negócios. Pode-se realizar de forma completa ou parcialmente, caracterizando portransações negócio a negócio, negócio a consumidor, intra- organizacional, com fácil e livreacesso. (NAKAMURA, P. I4). 
Para SMITH (2000), apud NAKAMURA (20II) o conceito de comércio eletrônico define-se como:

Negócios conduzidos exclusivamente através de um formato eletrônico. Sistemas que se comunicam eletronicamente uns com os outros são sistemas de e-commerce, e têm de ser capazes de funcionar normalmente com quaisquer aplicações da Internet que estiver planejando utilizar. Também se refere a quaisquer funções eletrônicas que auxiliam uma empresa na condução de seus negócios. (SMITH, 2000, p.74).

Em virtude dos aspectos analisados pelos autores acima, pode-se denominar comércio eletrônico como uma ferramenta de suma importância para o desenvolvimento organizacional, que tem a sua estrutura baseada no avanço tecnológico, objetivando a integralização de todos os processos internos das empresas, para que assim possa facilitar, sobretudo, a comunicação e a transferência de dados correta, auxiliando as organizações a conduzir seus negócios de maneira eficiente eficaz até na questão eletrônica. (NAKAMURA, 20II).

A figura I apresenta o modelo básico de comércio eletrônico, buscando mostrar todas as fases de uma compra feita eletronicamente, na visão do comprador e do vendedor.

Figura I - Modelo de Comércio Eletrônico

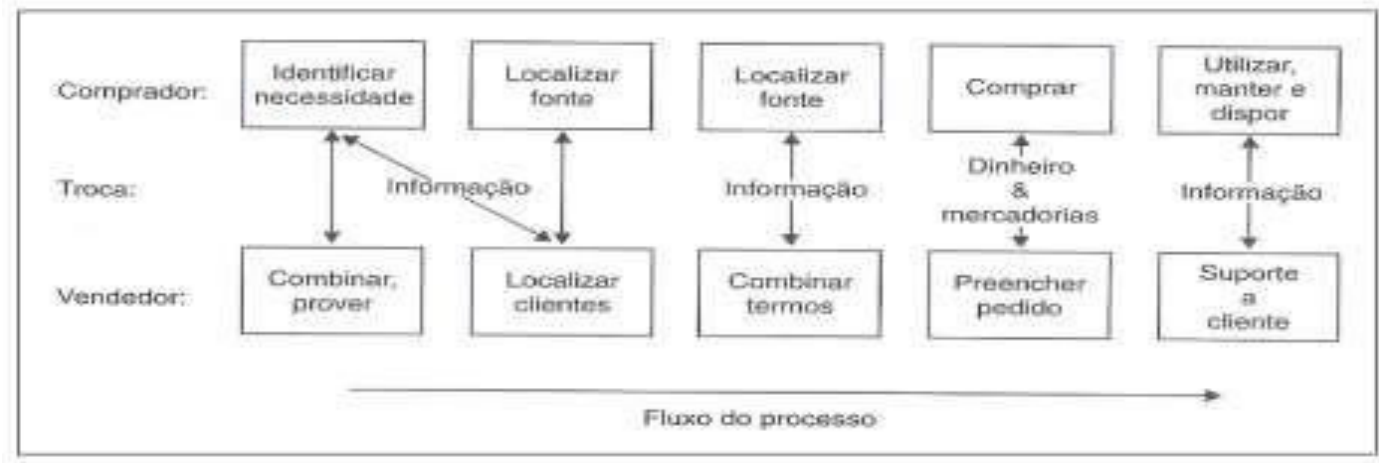

Fonte: Albertin, Alberto Luiz apud Nakamura

Com base na figura I, torna-se fácil compreender todo o processo de compra, desenvolvendo a concepção de que a informação I, deve ser monitorada e distribuída de maneira eficaz, para que assim não haja falhas nesse processo. (NAKAMURA, 20II, p.I4). Defende o autor que esse mecanismo imprescindível para as relações mercadológicas teve início desde o desenvolvimento da internet, na época pós guerra fria, onde a ArpaNet em 1969 desenvolveu a internet com o objetivo de integralizar os departamentos de pesquisa diminuindo significativamente as falhas recorrentes no processo de comunicação. Afirma ainda que o marco inicial do surgimento do e-commerce foi em 1979, quando um inventor inglês chamado Michael Aldrich criou as compras online. (NAKAMURA,20II).

\subsection{Tipos de comércio eletrônico}


O mercado compettitivo levou as empresas buscarem novos modelos de negócios e o e-business e e-commerce se apresentam como alternativas primoridiais para alavancar os negócios e ganhar competitividade. Entretanto, convem esclarecer que:

\begin{abstract}
e-business não é apenas o comércio realizado pela internet; isto é e-commerce, uma de suas partes. O conceito de e-business vai muito além e engloba todas as atividades de uma empresa. Podemos o definir como a integração de diversas atividades organizacionais através do auxílio de sistemas de informação, a qual possui a internet como meio de comunicação. (DANTAS, 20I8, p.I)
\end{abstract}

Entretanto, o foco deste arrtigo é o ecommerce a quem nos referimos como comércio eletrônico. Dantas (20I8, p.I) afirma que "e-commerce é a realização de vendas pela internet, sejam elas realizadas entre uma empresa e outra $\left(\mathrm{B}_{2} \mathrm{~B}\right)$, ou entre uma empresa e um cliente $(\mathrm{B} 2 \mathrm{C})$ ". Nesta perspectiva, apresenta-se a seguir os tipos de comércio eletrônico.

\title{
1.2.1 Business to Business (B2B)
}

É o comércio praticado pelos fornecedores e empresas, ou seja, de empresa para empresa. Onde é feito operações de compra e venda de produtos, informações e serviços por meio da web ou utilizando redes privadas partilhadas entre as empresas. Visa a interação entre empresas, de modo que as mesmas irão fornecer umas às outras os produtos, informações e serviços por intermédio da internet, ou seja, comercio eletrônico. (NAKAMURA, 20II, p.I6).

Segundo Nascimento, Silva e Santos (2009, p.2I) no comércio eletrônico B2B, a nova maneira de negociar on-line, tudo ficou mais simples e ágil, possibilitando um jeito de otimizar as cadeias de valores e aumentar o universo das empresas entre si .

A evolução do comércio eletrônico, possibilitou uma facilidade na comercialização entre empresas e na minimização do tempo e até mesmo do espaço. Através disso torna-se perceptível que o ato de comercialização entre empresas, seja pra vender produtos e/ou serviços, tornou-se mais rápido e prático, ou seja, houve um aprimoramento na otimização dos processos. (NASCIMENTO, SILVA e SANTOS, 2009, p.2I).

\subsubsection{Business to Consumer (B2C)}

Mendes (20II) define o comercio B2C como: "Negociação Eletrônica entre empresas e consumidores. Esta modalidade representa a virtualização da compra e venda. A diferença é que as pessoas escolhem e pagam os produtos pela internet". (MENDES, 20II, p.I).

Já para Nascimento, Silva e Santos (2009), pode-se conceituar o comércio B2C como:

As transações que ocorrem entre uma pessoa jurídica e uma pessoa física, ou seja, entre a empresa e o seu consumidor final. O B2C é uma maneira ótima da empresa se relacionar e interagir com os seus clientes finais, a fim de aumentar cada vez mais o seu fluxo de vendas. O consumidor entra no site, navega, escolhe o seu produto, a empresa leva este produto até o consumidor através 
Com base na declaração dos autores acima, pode-se dizer que essa ramificação do comércio eletrônico, tem por objetivo facilitar, significativamente, a comunicação entre as empresas e seus clientes.

\subsubsection{Consumer to Consumer (C2C)}

De acordo com Nascimento, Silva e Santos (2009, p.I), "É o tipo de transação que ocorre entre pessoas físicas, ou seja, consumidores finais, sem envolver nenhuma empresa no negócio. O leilão pela internet é um ótimo exemplo, onde é negociada uma infinidade de produtos com pessoas do mundo inteiro na rede. Pode-se definir comércio eletrônico como uma negociação realizada eletronicamente entre consumidores. (MENDES, 20II). Já para Nakamura (20II, p.I), é o "Comércio realizado entre usuários restritos a Internet, transação de bens e serviços apenas entre consumidores. Trata-se da comercialização entre consumidores diretamente ou através de uma empresa intermediária. Bom exemplo desse tipo de comércio é o leilão online, como Ebay e Mercado Livre."

\subsubsection{Government to Citizen (G2C)}

É uma subdivisão do comércio eletrônico que na visão de Nakamura (20II, p.I8) representa o comércio do governo ou outro órgão público com consumidor via web. Exemplo dessa atividade seria o pagamento de taxas de imposto, multas e tarifas através da Internet. Sendo um portal do governo oferecendo orientação e serviços aos cidadãos, voltado para área desde serviços, educação e empregos. Com o advento dessa ramificação do comércio eletrônico, as instituições governamentais estruturam suas relações com os cidadãos de uma forma mais eficaz, ampliando seu campo de comunicação e abrangência no que diz respeito aos consumidores, permitindo aos mesmos a facilidade de obter informações e/ou serviços, sem precisar sair de suas residências. (NAKAMURA, 20II, p.I8).

\subsubsection{Government to Business (G2B)}

São "negócios realizados entre o governo e as empresas, utilizando a internet como o meio de comunicação. Por exemplo, compras realizadas pelo governo usando a web como, pregão, licitações, tomada de preços, compra de fornecedores, etc”. (NAKAMURA, 20II, P. I9).

\subsection{Indicadores das transações realizadas eletronicamente nos últimos anos}

Com isso, é possível afirmar que o e-commerce teve uma evolução significativamente no que diz respeito as compras. O que deixa mais nítida a concepção de que o mercado tem evoluído bastante no quesito compras online, e que as pessoas estão se familiarizando com a aquisição de produtos e/ou serviços sem precisar sair de suas casas. (GAZIN ATACADO, 20I8, p.I).

Dados do Ebitwebshoppers (20I7), apud Gazin atacado (20I8, p.I), mostram que "mais de 
55 milhões de consumidores fizeram pelo menos uma compra virtual em 20I7. Isso representa um crescimento de $15 \%$ no número de consumidores online ativos no Brasil" conforme apresentado na figura 2 a seguir.

Figura 2 - Evolução dos e-consumidores

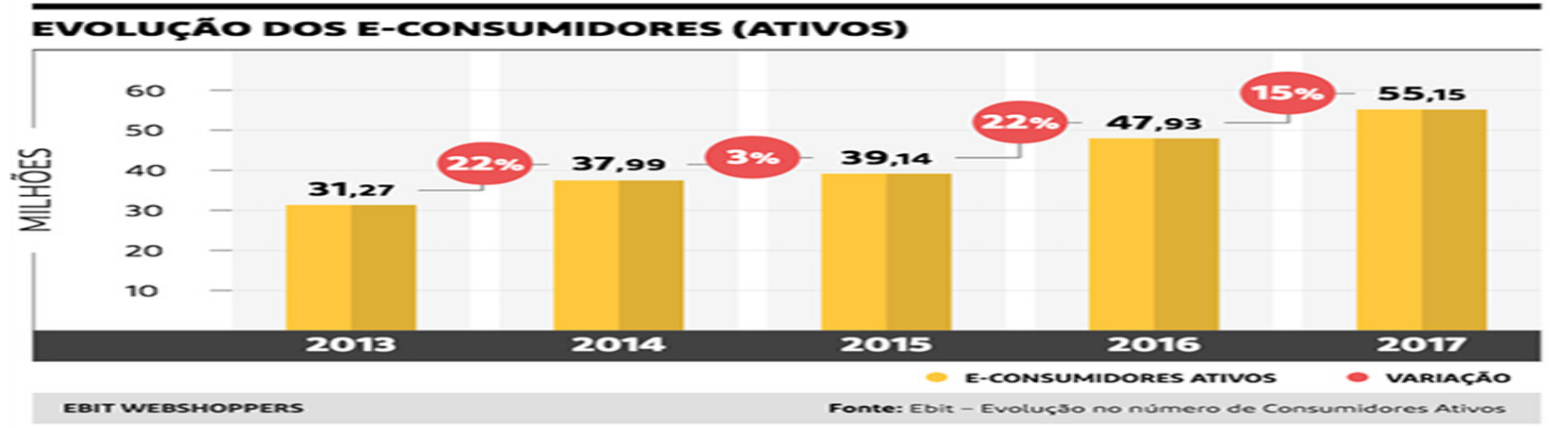

Fonte: https://www.fecomercio.com.br/public/upload/editor/ws38_vfinal.pdf

A figura 3 a seguir mostra a evolução do número de pedidos online nos últimos anos.

Figura 3 - Número de pedidos no e-commerce

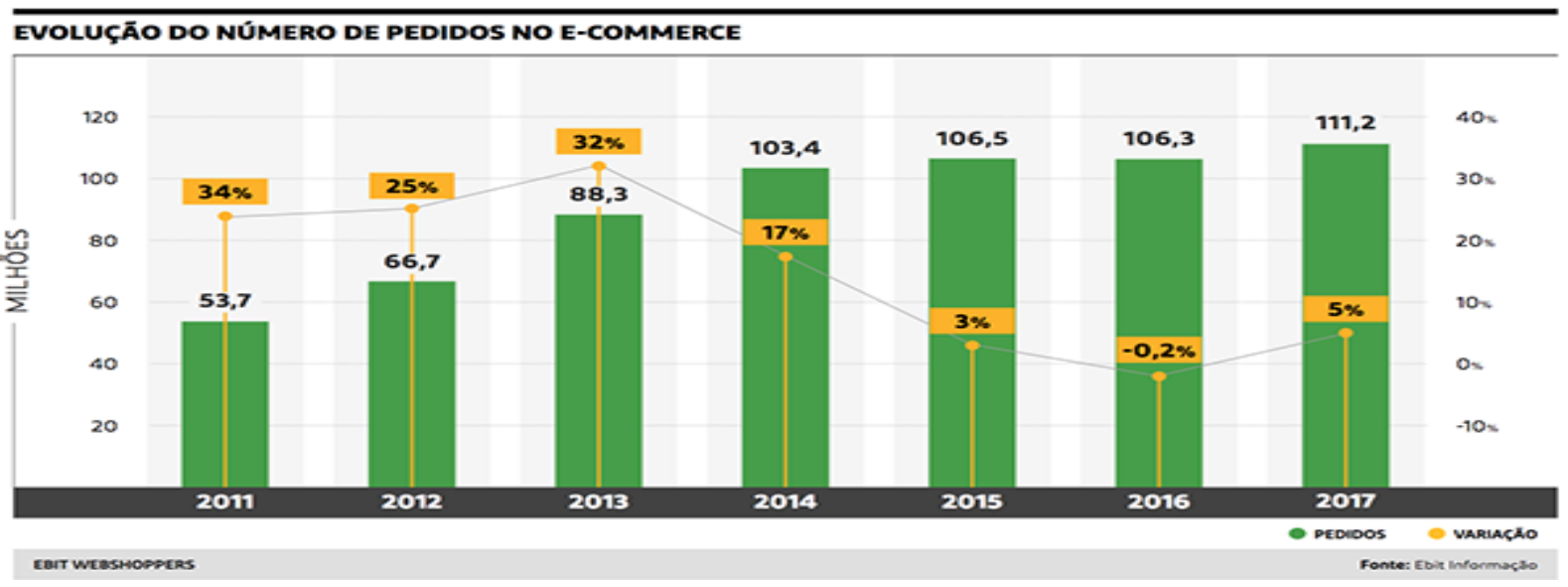

Fonte:https://www.fecomercio.com.br/public/upload/editor/ws38_vfinal.pdf

Através da figura 3 acima, compreende-se que o aumento ocorrido no que se diz respeito ao número de pedidos realizados através do e-commerce, é bastante significativo, totalizando um acréscimo de 5\% no ano de 2017 com relação ao ano anterior, o que indica, obviamente que inúmeras pessoas estão adentrando por essa ramificação da comercialização com o passar do tempo como afirma Ebitwebshoppers (20I7), apud Gazin atacado (20I8, p.I).

Vale ressaltar que dentro desses 55 milhões de internautas que compraram pelo menos uma vez pela internet no ano de $2017,49,8 \%$ dos mesmos realizaram suas compras a vista, significando assim um aumento em 7,6\% com relação ao ano anterior. A figura 4 a seguir demonstra as formas de pagamentos realizadas nos anos de 2016 e 20I7. (EBITWEBSHOPPERS (20I7), APUD GAZIN ATACADO, 20I8, P.I). 
Figura 4-Formas de Pagamento compras no e-commerce

\section{PRINCIPAIS FORMAS DE PAGAMENTO*}

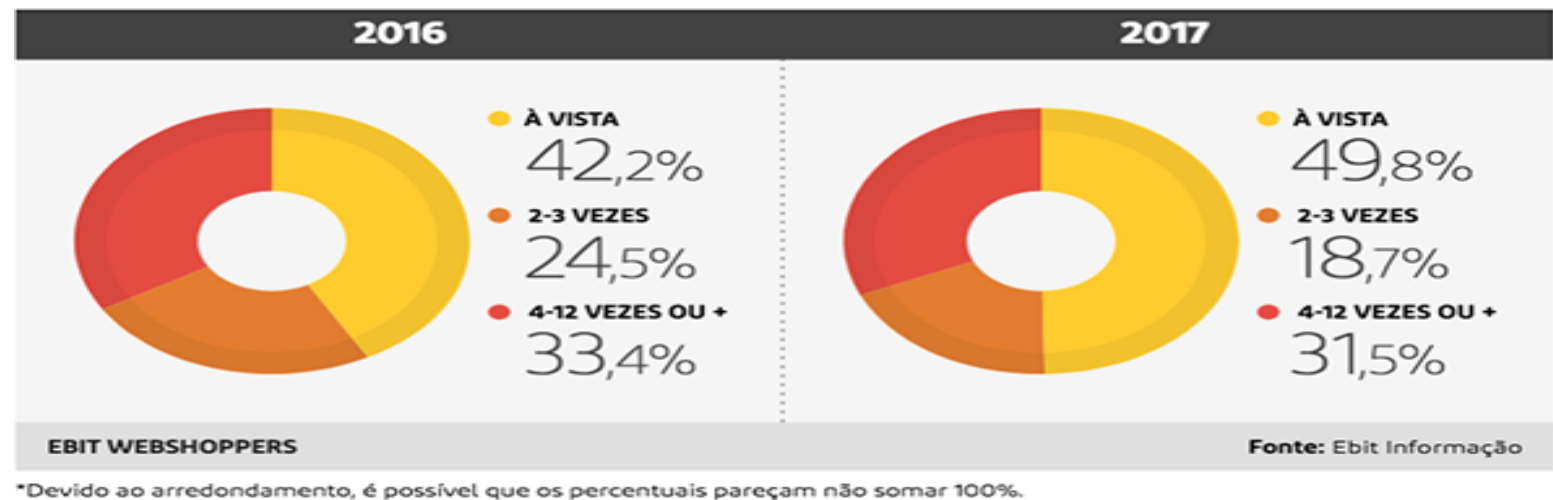

Fonte: : https://www.fecomercio.com.br/public/upload/editor/ws38_vfinal.pdf

Dentre os produtos solucionados através das compras eletrônicas, existem alguns que se destacam a nível de volume de pedidos, e outros no quesito volume financeiro conforme mostra a figura 5 a seguir.

Figura 5- Produtos mais destacados

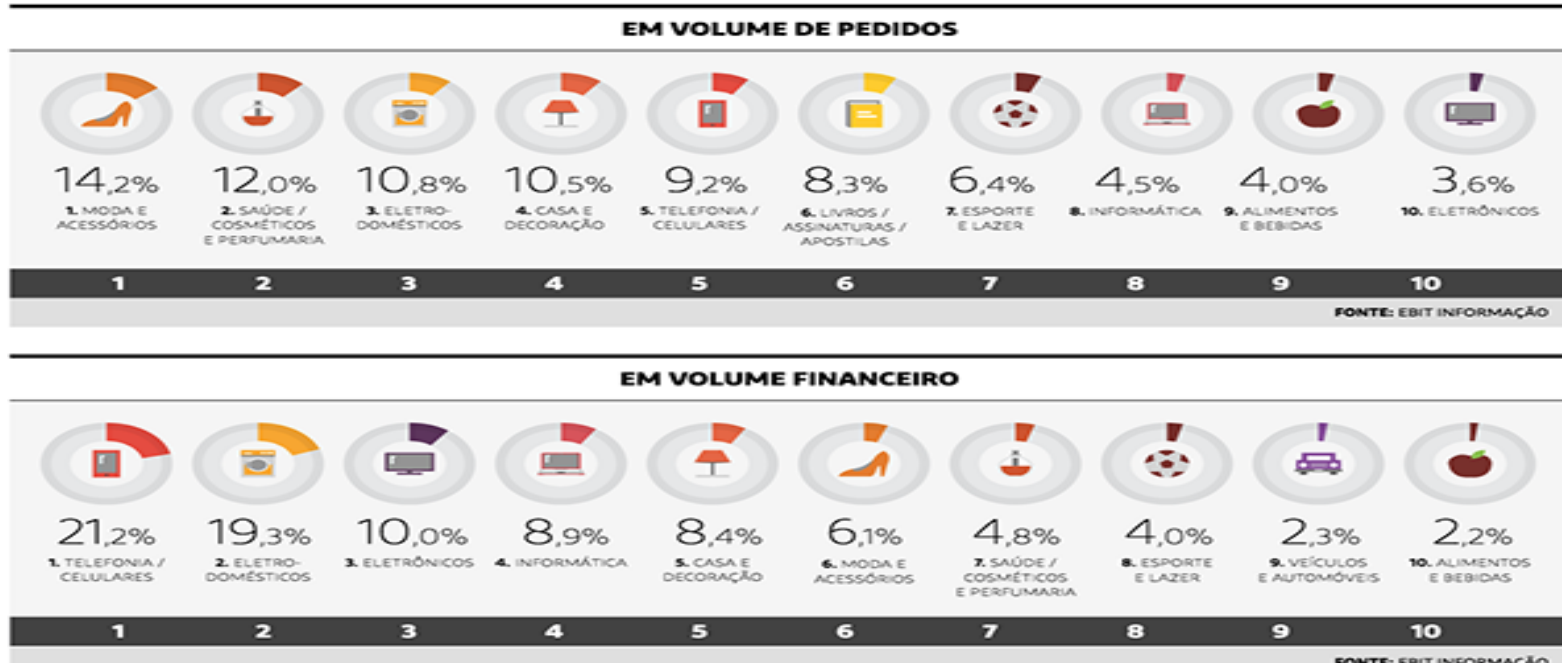

Fonte:https://www.fecomercio.com.br/public/upload/editor/ws38_vfinal.pdf

Conclui-se ao analisar a figura 5 acima que os produtos mais solicitados nas compras pelos clientes foram os produtos dos segmentos de Moda, Saúde/Cosméticos e Eletrodomésticos, e os produtos que tiveram maior movimentação financeira foram os das categorias de Telefonia, Eletrodomésticos e Eletrônicos (EBITWEBSHOPPERS (2017), APUD GAZIN ATACADO, 20I8, p.I).

Vale a pena incrementar a perspectiva de evolução do e-commerce sobre o ponto de vista da entidade Ebit (20I7), apud Gazin atacado (20I8), que visam afirmar a prerrogativa de que a evolução desse mecanismo de transação comercial tecnológico, chegará ao ápice de I2\% a 
mais do que no ano interior, alcançando os inacreditáveis $\mathrm{R} \$ 53,5$ bilhões de faturamento.

A figura 6 a seguir mostra nitidamente a perspectiva de evolução do e-commerce de acordo com as análises anuais realizadas pela entidade Ebit (2017), apud Gazin Atacado (20I8).

Figura 6: Faturamento do e-commerce de 2011 a 2018 (parcial).

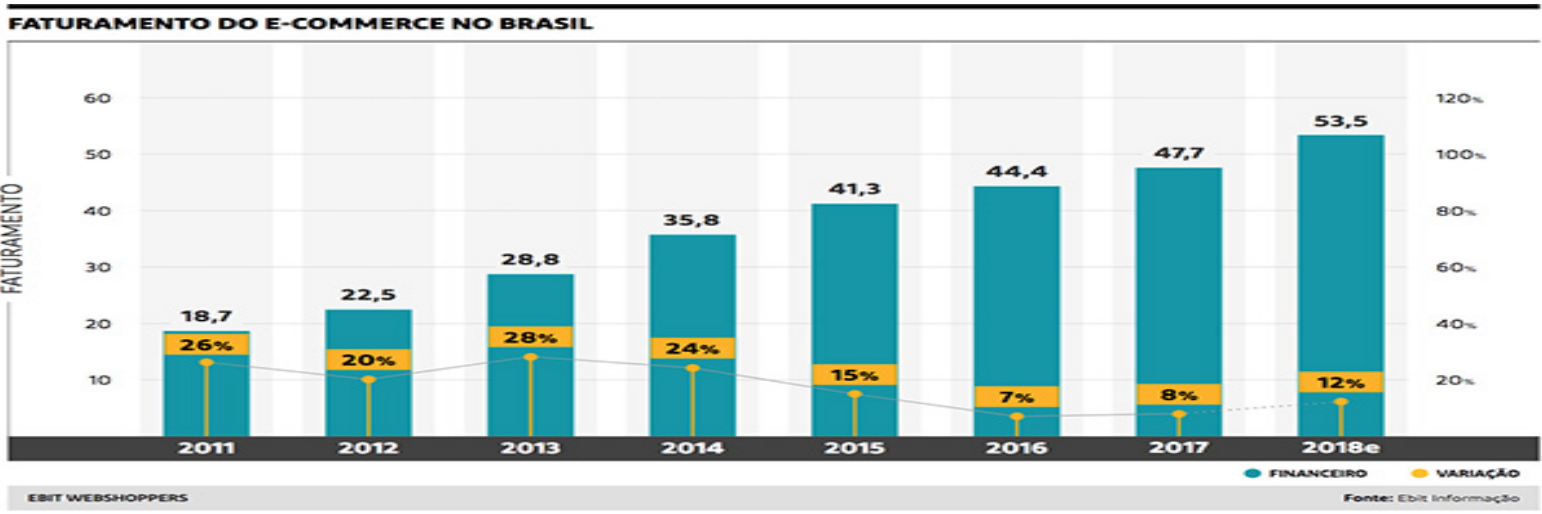

Fonte:https://www.fecomercio.com.br/public/upload/editor/ws38_vfinal.pdf

\subsection{O papel da logística no comércio eletrônico}

A logística pode ser definida como:

Estudo de como a administração pode prover melhor nível de rentabilidade nos serviços de distribuição aos clientes e aos consumidores através de planejamento, organização e controle efetivos para as atividades de movimentação e armazenagem que visem facilitar o fluxo de produtos (BALLOU, I993, apud RAMOS, 20I0).

Através disso, percebe-se o que a função da logística é administrar todas as operações necessárias no que se diz respeito a movimentação dos produtos, para que os mesmos estejam sempre no lugar certo, na hora certa, ao menor custo possível (BALLOU, I993, apud RAMOS, 20IO).

Também vale apena acrescentar a concepção de que a logística está cada vez mais interligada com os produtos, tendo em vista que ela engloba todas as operações existentes dentro do espaço entre o recebimento da matéria-prima para a transformação do produto, até a entrega no consumidor final, sistematizando todo o processo, deixando-o de forma mais eficiente e eficaz, buscando amenizar os empecilhos recorrentes dos seus processos e, manter todas as atividades centralizadas em um único denominador, tendo a objetividade de gerar um benefício coletivo a nível logístico e assim disponibilizar o produto para os clientes de acordo com o estabelecido no momento da compra (BRITO, SOUZA, PAIVA, GOMES, MORAES \& SILVA, 20I2).

De acordo com Fleury (2000): 
a logística numa das principais barreiras ao desenvolvimento do e-commerce, especialmente no caso do comércio business to consumer - $\mathrm{B}_{2} \mathrm{C}$, envolvendo produtos físicos para o consumidor final (...) As estimativas existentes são de que as entregas porta a porta realizadas pelas empresas de comércio virtual custam duas a três vezes mais caro do que as entregas do comércio tradicional realizado entre empresas (FLEURY, 2000, pI).

Com isso, subentende-se que à medida que a venda pela internet vem obtendo sucesso, surge um problema mais crítico no que diz respeito à comercialização eletrônica, a logística.

Essa problemática desenvolveu-se pelo fato de que existe uma mudança no que diz respeito às características dos pedidos feitos pelos clientes, onde, consequentemente cria-se uma necessidade de aprimoramento dos sistemas logísticos das empresas atuantes nesse segmento, para que as mesmas possam continuar otimizando seus processos de distribuição, atendendo assim, os prazos estabelecidos no ato da venda. (FLEURY, 2000).

Através do entendimento proporcionado por intermédio da observação da tabela acima, compreende-se que existe uma necessidade por parte dos sistemas logísticos no que diz respeito ao atendimento das demandas existentes nesse seguimento de comércio, que por sinal é o que causa mais dificuldades as empresas na questão da distribuição, devido a mudança significativa nos pedidos, que antes eram realizados por clientes conhecidos, agora passa a ter uma infinidade de clientes, onde não se tem mais a precisão de quem de fato está esperando o produto chegar até a sua casa (FLEURY, 2000).

Fleury (2000) ainda vai dizer que:

\begin{abstract}
As empresas envolvidas com e-commerce estão começando a perceber que para atender pedidos diretamente do consumidor final, torna-se necessário possuir centros de distribuição que permitam a execução de picking ao nível de itens individuais, com alto grau de eficiência, além de sistemas que possibilitem a administração de uma enorme quantidade de pedidos, compostos de um pequeno número de itens, e efetuados muitas vezes por novos clientes, sobre o qual não existem informações cadastrais, seja do ponto de vista comercial, seja do ponto de vista de localização. (FLEURY, 2000, p.I).
\end{abstract}

É perceptível a compreensão de que a mudança no cenário mercadológico a nível de comercialização, exigiu e exige até os dias de hoje, uma série de mudanças no que diz respeito as estruturas desenvolvidas pelas organizações para o atendimento aos pedidos dos clientes, para que assim as mesmas continuem realizando todos os seus processos, desde a venda até a distribuição do produto/serviço, com a eficiência, eficácia e efetividade necessários, e assim possa agradar a clientela crescente desse segmento tão importante para a economia. (FLEURY, 2000).

A Figura 7, a seguir, apresenta as principais diferenças entre a logística tradicional e a do e-commerce business-to-consumer. 
Figura 7 - Logística tradicional versus logística do e-commerce

Tabela 1

Principais diferenças entre a logistica tradicional e a logistica do e-commerce

\begin{tabular}{|c|c|c|}
\hline & $\begin{array}{l}\text { LOGISTICA } \\
\text { TRADICIONAL }\end{array}$ & $\begin{array}{l}\text { LOGISTICA DO } \\
\text { E_COMIMIR CE }\end{array}$ \\
\hline Típo de carregamento & Paletizado & Pequenos pacotes \\
\hline Clientes & Conhecidos & Desconhecidos \\
\hline Estilo da demanda & Empurrada & Puxada \\
\hline F1uxo do estoque $/$ pedido & Unidirecional & Bidirecional \\
\hline $\begin{array}{l}\text { Tamanho médio do } \\
\text { pedido }\end{array}$ & Mais de $\$ 1000$ & Menos de $\$ 100$ \\
\hline Destinos dospedidos & Concentrados & Altamente dispersos \\
\hline Responsabilidade & Um único elo & Toda cadeia de suprimento \\
\hline Demanda & Estáve1 e consistente & Incerta e fragmentada \\
\hline
\end{tabular}

Fonte: Fleury (2000)

De acordo com a TranspoBrasil (20I7,p.I); "realizar a gestão logística de um e- commerce não é uma tarefa fácil. Existem diversos desafios e fatores críticos que podem surgir ao longo do processo de expedição da mercadoria e levar o embarcador a enfrentar uma série de problemas operacionais ".Dentre as inúmeras dificuldades e desafios encontrados durante o processo de expedição das mercadorias para a futura distribuição, pode-se destacar:

a) Atender diferentes tipos de clientes; b) Transportar os vários tipos de produtos; c) Estabelecer uma política de frete acessível a todos; e, d) Escolher a transportadora adequada.

Sobre a questão do atendimento aos diferentes perfis de cliente, a TranspoBrasil (20I7) vai dizer que um e-commerce precisa estar preparado para atender a diferentes perfis de clientes. Além de procurar compreender as características e jornadas de compra de cada consumidor ou empresa, é preciso organizar a sua logística para entregar as mercadorias de casa em casa ou nos estabelecimentos comerciais. Assim como Fleury (2000) afirmou que houve uma mudança no que se diz respeito a sistemática da logística com o advento do e- commerce, a TranspoBrasil (20I7), intensifica essa mudança deixando claro que o perfil dos clientes se encontra diversificado, ou seja, houve uma mudança significativa nas relações comerciais, onde, hoje se tem uma variedade de clientes, que por sua maioria, são desconhecidos das empresas atuantes no e-commerce. Acerca da questão de transportar vários tipos de produtos, a TranspoBrasil (2017, p.I ), discorre que "assim como uma loja virtual pode receber pedidos de diferentes perfis de clientes, é possível que ela realize a venda de produtos variados (com volumes e pesos diferentes) que, de alguma forma, precisam chegar de forma segura e eficiente para os consumidores". Desta feita, a partir do momento em que uma empresa se dispõe a atuar no cenário do e-commerce, ela precisa ter em mente a concepção de que irá atender a clientes de diversos tipos, que obviamente, solicitam inúmeros produtos, deixando nítida a compreensão de que os produtos a serem distribuídos não seguem mais aquele padrão de operacionalização logística no transporte e distribuição dos mesmos, pois, haverá uma mudança significativa no que se diz respeito a variedade dos produtos, tendo em vista que o volume e tipo de produtos variam, e no cenário 
competitivo do e-commerce, a empresa que realizar a venda de seus produtos, tendo os mesmos características e especificações diferentes, terá de realizar o transporte de maneira estratégica, para que possa realizar a operação sem acarretar custos para si, ou atrasar no que diz respeito ao atendimento do pedido. (TRANSPOBRASIL, 20I7).

Para se estabelecer uma política de frete que seja acessível a todos os consumidores adeptos ao sistema do e-commerce, a TranspoBrasil (20I7) aconselha que "e preciso ter uma política de cobrança de frete estabelecida, em que você avalia todos os custos envolvidos em uma campanha de frete grátis, entendendo o valor das variáveis e potenciais devoluções dentro de uma cobrança de frete, alcançando, assim, mais lucros ao invés de prejuízos. (TRANSPOBRASIL, 20I7, p.I).

Assim, torna-se necessário reiterar que se as organizações não conseguirem estabelecer uma política de frete acessível aos consumidores, obviamente as mesmas irão obter um enorme problema para os seus negócios. O que se precisa fazer é entender a realidade do negócio a qual a organização está inserida, ter em mente todos os custos envolvidos nesse processo que envolve desde a compra do produto por parte do cliente até a sua movimentação para distribuí-lo em direção ao local correto, para que assim as organizações estabeleçam preços cada vez mais coerentes com a sua realidade do negócio, e possam continuar vendendo e distribuindo produtos (seja por intermédio de operadores logísticos e/ou através de sua própria estrutura), sem comprometer o poder de compra do cliente cobrando altos preços, ou a sua estrutura financeira no caso de inviabilidade do preço do frete, devido os custos serem maiores (TRANSPOBRASIL, 20I7).

No quesito de escolher uma transportadora adequada para operar a distribuição dos produtos, as empresas atuantes no e-commerce precisam ter em mente que uma escolha errada nesse aspecto, pode comprometer toda a imagem da empresa e assim, levá-la ao declínio. (TRANSPOBRASIL, 20I7).

\subsection{O surgimento das infovias, sua definição e importância dentro da logística do e- com- merce}

Diante de todo esse processo de evolução no que diz respeito ao cenário tecnológico das comercializações no mercado, sabe-se que a logística procura ser uma aliada extremamente forte das empresas, no que diz respeito a fornecer o auxílio necessário para que os produtos sejam entregues de forma ágil e rápida aos consumidores, satisfazendo-os não somente no quesito "comprar online", mas também no problema referente ao tempo de espera do mesmo. (FLEURY, 2000).

Vale a pena acrescentar que os modais logísticos atuais foram suficientes para atender a demanda existente no mercado, no entanto, através da evolução tecnológica e da mudança comportamental dos consumidores, é imprescindível reiterar que uma nova forma de distribuição que não se inclui nos modais convencionais, foi desenvolvida, a chamada infovia. (HORTA e MASCARENHAS, 20I8). 
Para o CFA (2013), apud Horta e Mascarenhas (20I8):

\begin{abstract}
O modal infoviário - criado com o advento da Tecnologia da Informação (TI) - permite o trafego de uma enorme quantidade de dados que facilitam os processos no transporte de cargas. Além de informações é possível transportar pelas infovias uma série de mercadorias como jornais, livros, projetos gráficos, fotos, músicas, filmes, serviços em Educação a Distância e outros produtos de informação que podem ser entregues quase instantaneamente em qualquer lugar do planeta. (CFA, 2013, p. 23, apud HORTA e MASCARENHAS, 20I8).
\end{abstract}

De acordo com a definição acima, torna-se viável reiterar que o modal infoviário auxilia as organizações no que diz respeito ao tráfego das informações, permitindo-as gerenciar todas as suas operações logísticas de forma mais sistêmica, eliminando certos gargalos a nível de informações que podem afetar significativamente nos processos logísticos planeta. (CFA, 20I3, p. 23, apud HORTA e MASCARENHAS, 20I8).

Para Tapajós (2007), apud HORTA e MASCARENHAS (20I8):

\begin{abstract}
A tecnologia da informação é fundamental para entender as complicadas cadeias de suprimento e de distribuição física. Os operadores logísticos não são meras transportadoras. Operam toda a inteligência da rede logística, da origem ao destino final. É nesse contexto que se estabelece o chamado "transporte infoviário", com a internet como a grande via, onde se "navega" transportando informação, utilizando como veículos as soluções web em TI, aliada às novas Tecnologias em telemática. (TAPAJOS, 2007, apud HORTA e MASCARENHAS, 20I8)
\end{abstract}

Vale argumentar que a medida que os operadores logísticos se munem da utilização das infovias, eles começam a operar todo o processo logístico com sucesso, realizando de fato o transporte infoviário, tendo a internet como a via que permite a transferência de dados, fazendo com que as informações sejam transportadas a medida que seja necessário, beneficiando a todos com o eficiente fluxo de operações, que permitirá, (ao menos dentro de sua abrangência) o perfeito funcionamento das atividades logísticas. (HORTA e MASCARENHAS, 20I8).

Como se pode entender, um dos maiores problemas no que diz respeito ao atendimento dos pedidos realizados eletronicamente é a mensuração das informações, pois, à medida que não tem sem as informações corretas a respeito dos clientes, é nítida a compreensão de que possivelmente haverá um problema na entrega do produto solicitado. (FLEURY, 2000, pI).

Vale acrescentar que a partir do momento que os números das transações comerciais eletrônicas avançam demasiadamente, os problemas com relação ao gerenciamento das informações tendem a aumentar também se as organizações não investirem na criação de novos modelos logísticos para o atendimento dos pedidos realizados (FLEURY, 2000, pI).

Com base nas afirmações de Fleury (2000), pode-se afirmar que uma solução que vem se identificando como adequada é o sistema logístico "ponta a ponta". 
Segundo a Forrester Research, este modelo é uma extensão do sistema utilizado por algumas empresas de venda por catálogo e implica na visibilidade do pacote transportado, bem como na continuidade do serviço prestado, desde o momento da compra até o momento da entrega (FLEURY, 2000, P.I).

Segundo a Forrester research, apud Fleury (2000): esse modelo possui três princípios básicos, a)Fortalecer o relacionamento com o Cliente, b) Focar em pacotes e não em pallets, e,

c) Entrega porta à porta. Sobre a questão do fortalecimento do relacionamento com os clientes, a Forrester research, apud Fleury (2000, p.I), afirma:

\footnotetext{
O cliente deve ser informado de todos os detalhes referentes ao ciclo completo do pedido, assim como acerca da disponibilidade dos produtos, previsão de entrega e custo total da transação. As empresas devem ser pró-ativas no envio de informações relativas ao pedido do cliente, especialmente quando as metas previamente estabelecidas no momento da compra não puderem ser cumpridas.
}

A medida que as empresas procurarem estabelecer uma melhor relação com os clientes, elas, sem dúvida alguma, serão submetidas a obrigação de manter os clientes sempre informados no que diz respeito a situação de seus respectivos produtos solicitados, se estão a caminho, e em qual parte do caminho estão, ou seja, as empresas precisam fornecer a clientela, todo o suporte informacional durante o tempo de finalização da compra até o tempo da aquisição física do produto em suas respectivas residências, para que assim, ainda que ocorra algo indesejado com o produto em destino, o cliente se satisfaça ao menos pelo serviço de atendimento e apoio prestados pela organização. (FLEURY, 2000).

No aspecto de focar em pacotes e não em pallets, a Forrester Research, apud Fleury (2000, p.2), defende que "As empresas devem se preparar para um grande fluxo de pedidos compostos de poucos itens e configurar seu sistema logístico de modo a obter o nível de serviço. As empresas que desejarem se estabelecer de uma forma cada vez mais sólida nesse cenário evolutivo do comercio eletrônico, precisam estabelecer um sistema logístico em que haja uma preparação para operacionalizar a gigantesca demanda de pedidos compostos, realizados pelos clientes.

Neste sentido, as empresas conseguirão realizar toda a operacionalização e distribuição dos pedidos feitos pelos clientes, adaptando as naturezas de pedidos distintas, pois as mesmas estarão gerindo todas as suas atividades logísticas, baseadas em informações concretas e sólidas sobre a mercadoria, o cliente, etc, como também, deixarão as relações entre elas e a clientela cada vez mais fixas e maiores, deixando os clientes cientes de tudo o que acontece com suas respectivas mercadorias, desde o momento de preparação do pedido até a entrega do mesmo, e assim, trará melhoria para todo o processo, seja estrutural ou informacional. (FORRESTER RESEARCH, apud FLEURY, 2000, P.I).

\section{METODOLOGIA}


Para a realização do trabalho a metodologia adotada foi a pesquisa bibliográfica em sites especializados que de acordo com Macedo (1994, p. I3) apud Horta e Mascarenhas, 20I8):

É a busca de informações bibliográficas, seleção de documentos que se relacionam com o problema de pesquisa (livros, verbetes de enciclopédia, artigos de revistas, trabalhos de congresso, teses, etc.) e o respectivo fichamento das referências para que sejam posteriormente utilizadas na identificação do material referenciado ou na bibliografia final. (HORTA e MASCARENHAS, 20I8, P. IO)

A metodologia utilizada na realização deste trabalho foi uma pesquisa bibliográfica exploratória descritiva onde foi evidenciado as variáveis: comercialização eletrônica, transporte, distribuição e informação.

\section{ANÁLISE DOS RESULTADOS}

Com base nas variáveis relacionadas ao e-commerce, foi verificado que:

a) Comercialização eletrônica

Com relação a essa variável estudada neste artigo, pode-se dizer que nos últimos anos houve uma evolução muito significativa no que diz respeito a esse tipo de comercialização, onde, tendo uma estratificação com relação aos dados recorrentes da evolução desse mecanismo de comercialização, têm-se o valor significativo de $\mathrm{R}$ \$4,7 Bilhões de reais de faturamento no ano de 2017 , tendo uma alta de $8 \%$ com relação a 2016 , sem falar também que existe a perspectiva de que no ano de 2018 o e-commerce alcance, de faturamento, os incríveis R \$ 53,5 Bilhões de reais, tendo um crescimento com relação a 2017 , de I $2 \%$, o que faz reiterar que, cada vez mais, o número de adeptos a esse mecanismo de comercialização altamente evolutivo, vem aumentando de uma forma extremamente significativa.

\section{b) Transporte}

No que diz respeito cenário evolutivo do comercio eletrônico, percebe-se que o transporte das mercadorias/produtos comercializados eletronicamente, é feito através dos modais convencionais, que por sua vez supre a necessidade logística do país. Tendo em vista a mudança na parte logística em si com relação a entrega dos produtos vendidos através do comércio, se há uma necessidade no que diz respeito ao modal rodoviário, que por sinal, é o mais utilizado devido a estrutura logística do brasil, de permanecer cada vez mais adaptável as possíveis mudanças no que diz respeito a variedades de produtos transportados, para que assim o transporte de diversos produtos possa ser efetuado por este modal de forma eficiente e eficaz, fazendo com que o produto chegue nas mãos do cliente dentro do tempo estabelecido no momento da comercialização. 


\section{c) Distribuição}

Sobre essa variável, têm-se a concepção de que houve uma mudança significativa no que diz respeito a sua forma de operacionalização. Isso se deu devido a aparição de inúmeros clientes diferentes com relação a perfis, e consequentemente pedidos. Vale apena acrescentar que antes do avanço tecnológico expressivo no âmbito da comercialização, as empresas que se responsabilizam pela distribuição dos produtos comercializados, tinham uma logística tradicional, com tipos de carregamento básicos, onde se efetuava a paletização(pois não havia tanta variação do tipo de produto), tendo clientes conhecidos, com uma demanda empurrada estável e consistente, com um tamanho médio do pedido entre mais de R \$1000,00, e para maior facilidade, elas tinham os destinos dos pedidos concentrados. No entanto, no cenário atual, proveniente do avanço tecnológico e da evolução na forma de comercialização, a distribuição precisa se estabelecer como a forma mais competitiva das organizações atuantes no e-commerce, fazendo com que as empresas possam distribuir inúmeros tipos de produtos diferentes, para locais diferentes, tendo clientes desconhecidos (pois são inúmeros), com um tamanho médio do pedido de menos do que $\mathrm{R} \$ \mathrm{I} 00,00$, e com o tipo de carregamento estruturado para pequenos pacotes, da melhor forma possível, fazendo com que as empresas possam oferecer não apenas o serviço eletrônico de vendas, mas também o serviço de distribuição do produto, de forma eficiente, eficaz e efetiva, ampliando assim o seu espaço nesse mercado altamente competitivo.

\section{d) Informação}

Com relação a essa vertente estudada durante a produção desse artigo, percebeu-se que os maiores problemas no que diz respeito a distribuir os produtos de forma correta, para a pessoa correta e no lugar e tempo correto, se dão devido a falta ou falha no gerenciamento das informações. A partir do momento que as empresas que operacionalizam a entrega dos produtos comercializados eletronicamente, estão munidas das informações necessárias e corretas acerca do destinatário, certamente a distribuição desses produtos será feita de forma eficiente e eficaz, mas no momento em que há a falta de alguma informação importante no processo de venda ( pois a maior parte das informações são obtidas nesse momento), torna-se difícil entregar o produto no destino final dentro do tempo estabelecido. O crescimento significativo do número das transações comerciais eletrônicas, obriga as empresas a priorizarem cada vez mais a coleta das informações relativas as entregas de seus produtos de maneira eficaz, e a gerenciá-las de forma ágil, para que assim possam realizar todo o processo de distribuição dos pedidos, com eficácia e eficiência. Também é viável reiterar que o surgimento das infovias é algo que facilitará bastante as empresas a gerenciarem distribuírem informações necessárias para seus clientes, onde, agora os clientes podem ter a relação real do estado de suas mercadorias, ou seja, caso a mercadoria não chegue, a empresa terá de possibilitar ao cliente o status de seu pedido, constando o local em que ele se encontra e uma possível previsão de chegada no destino final. Isso, sem dúvida alguma, é algo que fortalecerá as organizações com relação a confiabilidade, pois, mesmo que o produto não tenha sido entregue no momento, elas estarão fornecendo aos seus clientes as informações recorrentes ao atraso, deixando-os seguros e cientes de tudo o que acontece. 


\section{CONSIDERAÇÕES FINAIS}

O presente artigo buscou identificar o papel da logística dentro do comércio eletrônico. A logística, quando gerenciada de forma correta, traz o sucesso para as organizações que atuam nesse cenário altamente competitivo. Sabe-se que a evolução tecnológica foi o fator principal para que a comercialização chegasse a esse ponto, ou seja, para que pudesse ser realizada de forma eletrônica, através de um computador, smartphone, etc, precisando apenas de uma conexão com a internet e um navegador.

No entanto, quando se fala de logística, o aspecto central, que faz com que muitas empresas se diferencie das outras, independente da forma de comercialização, é o tempo de entrega do produto. Hoje o que se tem por mais diferencial no que diz respeito a todas as organizações, e prioritariamente as atuantes nesse tipo de negócio é a distribuição. Pois, a compra pode ser até rápida, mas o tempo de espera para receber o produto por parte do cliente é o que a empresa tem de oferecer por diferencial competitivo, tendo em vista que o cliente compra pela internet com a confiança de receber o seu produto o mais rápido possível, independente de onde o seu produto esteja. Neste sentido, o papel fundamental da logistica no comércio eletrônico é asseguar a satisfação do cliente disponibilizando o produto nas condições acordadas e contribuindo para a fidelização do cliente.

Vale ressaltar que o advento de inúmeros clientes à essa prática de comercialização, fez com que as empresas tivessem de estruturar os seus processos logísticos, para que assim, as mesmas pudessem continuar oferecendo seus produtos e serviços com qualidade no que se diz respeito ao tempo, pois no cenário atual do comercio eletrônico, as empresas precisam realizar entregas de produtos extremamente diferentes, para locais distintos e pessoas desconhecidas, logo, se a logística da empresa não se adequar a essa nova sistemática de entrega de pedidos, a mesma perderá o seu espaço, pois, a maioria dos pedidos realizados no e-commerce é através do comércio $\mathrm{B}_{2} \mathrm{C}$, onde inúmeros clientes desconhecidos, de lugares bastante diferentes, solicitam pedidos consideráveis pequenos, o que faz com que as empresas necessitem estruturar todo o processo de distribuição, de forma eficiente ,para que todos os clientes se satisfaçam não apenas com o processo de comprar rapidamente pela internet, mas também de receber o produto dentro do tempo concordado no ato da compra.

\section{REFERÊNCIAS}

CONCEITO DE. Conceito de Comércio. Disponível em: https://conceito.de/comercio . Acesso: I3/05/20I8

CRUZ, Lucineide. O desenvolvimento do e-commerce no Brasil. Disponível em:http:// www.administradores.com.br/artigos/academico/o-desenvolvimento-do-e-commerce-nobrasil/IOI304/. Acesso: I7/06/20I8.

CULTURA MIX. A história do comércio. Disponível em: http://cultura.culturamix.com/ curiosidades/a-historia-do-omercio. Acesso: 06/05/20I8. 
DANTAS, Tiago. E-business, Brasil Escola. Disponível em: https://brasilescola.uol.com.br/ informatica/ebusiness.htm. Acesso em:I4/04/20I8.

DRUCKER, Peter. O futuro já chegou. Exame. Ano 34, nº 6, 22/03/2000, p. II2-I26.

FECOMÉRCIO. Webshoppers. Disponível em: https://www.fecomercio.com.br/public/upload/ editor/ws38_vfinal.pdf. Acesso :I8/06/20I8.

FIGUEIREDO, Iria Luppi. Histórico do Comércio Eletrônico. Disponível em: https://www. oficinadanet.com.br/artigo/I7I8/historico_do_comercio_eletronico. acesso: 11/06/2018.

FLEURY, Paulo. O Desafio Logístico do E-commerce. Disponível em: http://www.ilos.com. br/web/o-desafio-logistico-do-e-commerce/. Acesso em:05/6/20I8.

GAZIN ATACADO. Panorama do e-commerce no Brasil. Disponível em: http://blog. gazinatacado.com.br/e-commerce-no-brasil-2/ . Acesso em 05/06/20I8.

MENDES, Marcos. O Comércio Eletrônico no Brasil. Disponível em: http://www.cultura. ufpa.br/rcientifica/artigos_cientificos/ed_08/pdf/marcos_mendes3.pdf Acesso: I0/06/20I8.

MENDES, Rafael. Por que o frete é um problema no e-commerce? Disponível em: https:// asaplog.com.br/por-que-o-frete-e-um-problema-no-e-commerce/ Acesso em: 17/06/20I8.

SOUSA, Rainer.A história do comércio. Disponível em: https://brasilescola.uol.com.br/ historia/historia-do-comercio.htm Acesso: I2/05/20I8

TRANSPOBRASIL. 7 fatores críticos na logística de um e-commerce. Disponível em: http://www.transpobrasil.com.br/20I7/IO/20/7-fatores-criticos-na-logistica-de-um-e- commerce/ Acesso: 03/06/2018 